\title{
Categories and the Language of Metaphysics
}

\author{
Mirco Sambrotta*
}

Received: 9 May 2018 / Accepted: 2 October 2018

Abstract: The purpose of this paper is to better understand what ontologists are doing when they ask questions about the categories of the world. I will take Cumpa's attempts to find out the fundamental structure of the world as a case-study. In one of his latest paper (Cumpa 2014), he conceives the classical ontological question about the existence of the fundamental categories of the world (what are the fundamental categories of the world?) as a question about the category able to unify the two Sellarsian images of the world: the manifest and scientific images, considered as two different languages. According to him, the only category with such an explanatory power is the category of 'facts' (or 'state of affairs'): the fundamental category of what he calls 'the metaphysical language.' I will argue that if Cumpa takes the latter to be a broader language or framework, in Carnap's terms, common to both the ordinary and the scientific ones, then his proposal turns out to be rather problematic (as they are ultimately 'incommensurable'). On the other hand, if he understands it as external to both of them, then his solution ends up being meaningless and devoid of any cognitive content, with at best a practical character and/or an expressive function.

Keywords: Categorial ontology; sortalism; ontological disputes; scientific image; manifest image.

* University of Granada

Department of Philosophy, Faculty of Philosophy and Humanities, University of Granada, Campus de la Cartuja, 18011 Granada, Spain

$\triangle$ mirco.sambrotta@gmail.com

() The Author. Journal compilation (C) The Editorial Board, Organon F.

This article is distributed under the terms of the Creative Commons Attribution-NonCommercial 4.0 International Public License (CC BY-NC 4.0). 
"[T]he tendency represented by the running-up against the limits of language points to something.

St. Augustine already knew this when he said: What, you wretch, so you want to avoid talking nonsense? Talk some nonsense, it makes no difference!" (Wittgenstein L., On Heidegger on Being and Dread)

\section{Introduction}

In a recent paper, Cumpa proposes a new criterion for establishing the fundamental category of the world: 'the materialist criterion of world-fundamentality' (Cumpa 2014). According to such a criterion, the fundamental category is that with the greatest explanatory power at the time of reconciling the manifest image and the scientific image of the world. Starting from the well-known Carnapian distinction [see (Carnap 1950)] between questions of existence inside and outside a linguistic framework, ${ }^{1} \mathrm{I}$ will try to examine Cumpa's related argument in two different ways.

In the first one, I will interpret Cumpa's proposal as that of looking for the common fundamental category of both the manifest and the scientific image. In this way, I will consider his categorial question as being asked within a common framework to the two languages (the 'realistic' and the 'scientific' ones, as he calls them). That is to say, a broader framework in which the category he proposes, the category of 'facts,' is a common category shared by both, or at least the only one among the various alternatives proposed able of turning this function. Assuming that Cumpa's analysis is correct, the category of 'facts' will have greater explanatory power, hence a greater epistemic value compared to other categories taken into account. In order to defend such an interpretation of Cumpa's standpoint, I will try

1 The notion of 'framework' here is quite intuitive: the conjunction of the rules of use of some expressions and the circumstances in which such expressions work. That is, the system of linguistic expressions (key terms like substantives and predicates) and semantic rules (or at least core of rules, constitutive rules) governing those expressions. And, at the same time, the circumstances in which such expressions work. 
to point out that it is possible to allow for epistemic values only inside a given framework.

On the other hand, in the second one, I will understand Cumpa's proposal as an effort to find out the fundamental category of the world beyond and outside any framework, trying to answer the ontological question "which category does really exist?" in its external reading (according to Carnap's dictates). In this case, the conclusions he reaches play just an expressive function. By this I mean they cannot have any semantic or cognitive content at all (at least a straightforwardly factual content) and at best they can be understood as expressions of commitments to certain language choices. They turn out to be just expressions of commitments to adopt the categorial framework in which a specific category (in this specific case, the category of 'facts') occupies the fundamental level. And this not because of some presumed epistemic values that framework has over others, but rather because of some implicit practical virtues (perhaps, the practical advantages of coping with today's increasingly pressing demand to incorporate scientific expressions with those already in use in ordinary language?). Anyway, I will try to underline how the choice of one framework or another appeal to any epistemic value (as the greatest explanatory power), since epistemic values can be assessed only within a given framework. At most, indeed, one can appeal to some implicit practical virtues, which Cumpa should in this sense make explicit in his inquiry.

The remainder of the paper is divided along these lines: in the next Section, I will summarize Cumpa's solution to the fundamental category problem, drawing attention mainly to his (2014) paper. Then, in Section 3, I will assess his solution from a 'sortalist' point of view. I will present this first analysis of Cumpa's conclusions and lay out my principal worries about that solution (though, perhaps, not decisive). In Section 4, I provide an alternative reading. Following Carnap's well known distinction between 'internal' and 'external' existence questions, I will argue for an 'external' approach to categorial issues (and to ontological claims in general). Although promising respect to the previous one, that alternative does encounter some difficulties and does not avoid to pose some problems to Cumpa's model. Or, at least, it leads to rethinking the issue Cumpa raises in a totally different way. The concluding Section 5 consists of a short recap. 
As already mentioned, in what follows, my primary aim will be to provide a concise summary and sympathetic critique of Cumpa's solution. I say 'sympathetic' insofar as I believe he has gotten a great deal in his account of the fundamental structure of the world, making significant and original contributions to this important area of ontology and metaphysics. However, I find the particular solution he develops in (Cumpa 2014) potentially problematic or, at least, not sufficiently developed. While I do not think these concerns are quite as pressing as the ones facing Cumpa's account, they are weighty. Nevertheless, in the end, perhaps the primary lesson for those reflecting on the problem of the fundamental category structure of the world is just that further work may still be needed.

\section{The materialist criterion of fundamentality}

'Fundamental' is a much debated term in contemporary metaphysics. 'Fundamentality' is also the main concern of Cumpa's work in the last few years. ${ }^{2}$ Especially in (Cumpa 2014), he focuses on what he calls "worldfundamentality;" that is to say, the fundamental structure of the world. The question he seeks to answer deals with one of the most classic problems in ontology and metaphysics: "Is our world a world of Aristotle's ordinary substances, Locke's physical substances, Husserl's wholes, Wittgenstein's facts, Sellars's processes, or Quine's sets?" (Cumpa 2014, 319). In short, what are the most basic categories that make up our world?

Cumpa suggests that this long-standing dilemma is only possible to be solved by appealing to epistemic values, those in literature are generally labeled as 'theoretical virtues.' Nevertheless, according to him, the traditional epistemic values (or theoretical virtues) usually invoked in metaphysics, such as 'independence' and 'simplicity,' are old-fashioned and fruitless criteria to be used as a guide to find out the most fundamental category of the world. Thereby, he proposes to add a new epistemic value as a criterion of world-fundamentality to the existing catalog of independence and simplicity: the explanatory power. In particular, the explanatory power to

\footnotetext{
2 There are of course important issues here as to what we mean by 'fundamental;' on this subject, see (McKenzie 2011, 2014).
} 
account for the relation between 'ordinary world' and 'physical universe.' Therefore, the only categories he thinks can be considered fundamental are those which manage to understand the reconciliation of the ordinary and the scientific description of the world. Or better, he attempts to show that the fundamental categories are just those which have the explanatory power to account for the relation between the ordinary and the scientific image. According to such a criterion, which he calls "the materialist criterion of world-fundamentality," in order to establish whether or not an alleged category can be deemed as fundamental, metaphysicians should consider its explanatory power to account for the relation between the ordinary world and the physical universe.

Next, he argues that the only category which satisfactorily accounts for the relationship between the ordinary and scientific levels of thinghood is the category of 'facts' (or 'state of affairs'). And this leads him to conclude that "the world is a world of facts" (Cumpa 2014, 321). In order to demonstrate such an explanatory power of 'facts' to rationally reconstruct the supposed relation, he discusses first some classical alternatives to them as explanatory categories. First, he considers the cases of 'sets' and 'substances,' and he shows why such categories fail to account for the relationship between the two levels, despite the fact that they are usually held to satisfy the traditional criteria of fundamentality (such as 'simplicity,' for instance). Given the division in which the categories at stake are customarily compound, such as substance-accident, set-member or fact-constituent, just the latter has the epistemic primacy to manage to account for the relationship between the ordinary and scientific description of the world. As an example, he takes the 'arrangement of particles' of which a table consists and its 'perceptual properties' as the two constituents of a fact. And, in light of the above outlook, he maintains that just the fact-constituent division can account for the explanatory relationship between the arrangements of elementary particles of the physical universe and the emerging properties of the ordinary world (Cumpa 2014, 322).

Since it is not my intent here to question this particular point, I will not go into more detail on this stage of Cumpa's argument, so I will take for granted that the division between facts and constituents has the advantage, over other alternatives under consideration, to possess this cross-sectional 
character. The issue I am most interested in is the distinction, at the bottom of his view, between the ordinary and scientific levels. What does he exactly mean with 'ordinary world' and 'physical universe?' As he explicitly states, with those expressions he means something similar to what Wilfrid Sellars defined 'the manifest image' and 'the scientific image' [see (Sellars 1963)]. Therefore, by 'ordinary world' he means "an ordinary level of thinghood with which ordinary people are acquainted in their commonsensical and practical experiences" (Cumpa 2014, 319). On the other hand, by "physical universe' he means "a scientific level of thinghood with which scientists are acquainted in their experimental research, such as fundamental physics, chemistry, or biology" (Cumpa 2014, 320).

Here, in both Cumpa and Sellars, the background seems to be a unityof-science view ${ }^{3}$ that sees the sciences as forming a reductive explanatory hierarchy, with fundamental physics at the bottom, chemistry built on it, biology on it, the special natural sciences above them, and psychology and the social sciences hovering somehow above them, at least insofar as they deserve to count as 'real' sciences. The ideal is to be able to do all the explanatory work of the upper levels by appeal only to vocabulary and laws of the lower levels. ${ }^{4}$

The alleged fundamental categories of 'facts' should thus account for the world as a complex composed of ordinary objects and the imperceptible objects postulates by fundamental sciences. However, what is more important for the general aim of this paper is that Cumpa clearly considers the source of knowledge of these levels to be respectively the ordinary discourse and scientific theories.

3 Championed by Neurath and the first Carnap among others, and more recently endorsed by Kim (1992).

4 Yet today, hardly any philosopher of science would subscribe to the explanatory hierarchy central to the unity-of-science idea. It now seems clear that science works at many explanatory levels, and that generalizations available at one level cannot be replaced by those formulable in the vocabulary of other levels [see especially (Fodor 1974), (Putnam 1975), (Dennett 1991), and (Wilson 2008)]. The explanatory heterogeneity and incommensurability of the various sciences, from which no 'best realizer' emerges, is sometimes called the "Many Levels" view. Thanks to an anonymous referee for pointing this out. 
In order to ground the epistemology of 'commonsense realism' and 'scientific materialism,' he accordingly proceeds in the analysis of verbal behavior and scientific laws. What turns out to be at issue are ultimately 'the ordinary language' and 'the scientific language,' or better "the realistic language," ${ }^{5}$ as he calls the former, as opposed to the "the physicalistic language," as he calls the latter (Cumpa 2014, 320, 322).

In order to address the question concerning the relations between the descriptions and explanations whose home is in the manifest image and those whose home is in the scientific image (or better, in any scientific images), he conjectures that it is possible to build a cross-sectional language with the explanatory power of reconstructing the two images in one. He trusts in the possibility of 'a metaphysical language' (Cumpa 2014, 321) able to display an image of the world as a whole. That is to say, the world composed of the ordinary world and the physical universe. Metaphysical language is not either the realistic language or the scientific language, but at the same time it cannot dispense with both of them. And in this language, the fundamental category is, of course, that of 'facts.' In this way, Cumpa shifts to a special language that smells like the Ontologese and thereby revives hard metaphysical debates.

At this stage, the question I would like to raise is therefore whether the 'metaphysical language' must be taken as a common language to the ordinary and scientific ones, a language which both share (at least at the fundamental categorial level); or instead, it should be better understood as another language different from both of them (to some extent, beyond and outside of both of them). In the next chapter, I will try to develop this concern in the light of the well-known Carnap's distinction between 'internal' and 'external' ontological questions about the existence or reality of entities. Besides, in doing so, I will take a category to be fundamental if and only if it is not derived from another category in a language or framework.

5 Note that the language of the manifest image (the language of the ordinary lifeworld, both before and after the advent of modern science) does not only deploy normative vocabulary, but also deploys vocabulary to describe and explain. 


\section{A sortalist reading}

The divergence between the world-descriptions provided by physical science and common sense has led to some of the oldest and most persistent arguments for eliminating ordinary objects. For if, as some have thought, the descriptions of science compete with those of common sense, usually the former has primacy over the latter and we must accept that common sense descriptions of the world (as containing trees, battles, and basketballs) apply to nothing. Eliminativism about ordinary objects may seem a radical position to adopt but it is one that meshes with our understanding of contemporary physics, according to which there is only a limited number of certain fundamental kinds of elementary particles and four fundamental forces.

One of the strongest forms that such arguments can take, inspired but apparently not endorsed by the astronomer Sir Arthur Stanley Eddington, alleges not just that the descriptions or claims of physical science compete with those of common sense, but that there is a real conflict between them, a conflict that physical science wins. Thus, if the two are rivals, surely (it is said) the scientific view must win out at the expense of the common sense view, and we must deny the existence of ordinary objects in favor of an ontology sanctioned by physical science. The idea that the descriptions of the world provided by physical science conflict with those of common sense was initially advanced by Eddington's famous discussion of the 'two tables':

Yes; there are duplicates of every object about me - two tables, two chairs, two pens [...] One of them has been familiar to me from earliest years. It is a commonplace object of that environment which I call the world [...] It has extension; it is comparatively permanent; it is coloured; above all it is substantial [...] Table No.2 is my scientific table [...] My scientific table is mostly emptiness. Sparsely scattered in that emptiness are numerous electric charges rushing about with great speed; but their combined bulk amounts to less than a billionth of the bulk of the table itself. (Eddington 1928, ix-x)

The descriptions of the 'table of science', Eddington emphasizes, do not merely differ from the descriptions of the 'table of common sense', they conflict with it in various ways, e.g. that common sense table is 'substantial' 
and solid, while the scientific table is "nearly all empty space" (Eddington 1928, x) and so neither substantial nor solid. Quite similarly, Sellars himself maintains that, since each of them purports to be true and complete, any account which attempted to incorporate both the manifest and scientific images "would contain a redundancy" (Sellars 1963, 25). Eddington's attack has been taken up again more recently by Thomasson (2007), who defends an ontology of ordinary objects against eliminativist arguments. According to her, there can be a conflict between them only if the two sides are talking about the same thing. That is to say, in order to demonstrate a conflict one must show that the two descriptions are talking about the same thing with one asserting that it is, say, solid, and the other denying that it is solid. But, Thomasson maintains, any account of what there is presupposes a certain sortal framework. For either side, in order to make a definite claim, must employ some sortal term capable of establishing what is being talked about (and attributed or denied solidity). The sortal which common sense uses (and that Eddington uses) is "table." Nevertheless, it is at least doubtful that scientific theories use sortals such as "table." Susan Stebbing, for instance, famously argued that it is absurd to speak of the object of scientific description as a "table" at all (supposedly in competition with the familiar table) (Stebbing 1937, 54), since scientific objects are mostly 'simples.' We pretty clearly have examples of common sense and scientific discoveries speaking of the same things, in the same terms (and if they are not, the case for a conflict evaporates). However, this is precisely not the case regarding common sense claims about there being tables, apples, and tennis balls, and the claims of contemporary physics couched in terms of waves and particles.

In short, we can define 'sortalism' as the view that highlights the importance of sortal terms and concepts in establishing reference and the truth-conditions of metaphysical claims. ${ }^{6}$ In particular, here sortal considerations enter the picture insofar reference to things is fixed via some categorial framework. Hence, Thomasson concludes:

$6 \quad$ According to Jonathan Lowe (1989), that consists of three claims:

1. Sortal terms and concepts are (generally) associated with semantic principles that supply criteria of application and criteria of individuation and identity for anything that is to fall under them.

Organon F 26 (2) 2019: 186-206 
Scientific theories [...] do not use sortals such as 'table,' and if science and common sense are using sortals of different categories, the 'things' picked out by the two descriptions cannot be identical. (Thomasson 2007, 142)

Reference is only determinate to the extent that a term is associated with a categorial conception determined by the application and coapplication conditions associated with our terms. ${ }^{7}$ In other words, counting claims rely on identity claims, the truth-conditions for which are, she argues, category-relative (Dummett 1973/1981, 74; Geach 1962/1980, 63). Of course, categorial conceptions may be expressed in categorial terms (such as 'organism,' 'artifact,' etc.), which are just highly general sortal terms. And, according to the sortalist view, since the scientific image and manifest image are using sortals of different categories (associated with different application and coapplication/identity conditions), so that they are each concerned with different categories of entities and employ different characteristic sortal terms, we cannot say that the two descriptions conflict with each other. Likewise, we cannot say that there are true identity claims relating the descriptive terms in the vocabulary of the manifest image that refer at all and descriptive terms drawn from the vocabulary (or vocabularies) of the scientific image. ${ }^{8}$

2. Individuals may only be referred to, (re-)identified, and counted by (explicitly or tacitly) employing a sortal.

3. Individuals $a$ and $b$ can only be identical if they are of sorts with the same criteria of identity, and they meet those criteria.

7 According to Thomasson $(2007,2009)$ 'application conditions' are the rules for using nominative terms which establish in what situations they are properly applied, and where they are to be refused; on the other hand, 'coapplication conditions' are the rules for using nominative terms which establish under what conditions we may use the term to refer again to the same entity.

8 These are in general what we can call 'strongly cross-sortal' identity claims: claims relating terms whose governing sortals are governed by quite different criteria of identity and individuation. But, strongly cross-sortal identities are never true. For the different criteria of identity and individuation associated with the sortals. The claim that strongly cross-sortal identities are never true is a radical one. But, if all that is right, then the relation between the objects referred to in the manifest image and those referred to in the scientific image cannot be identity. 
Moreover, since such images are distinguished from each other in terms of the sortal and categorial terms each employs (with the manifest image omitting terms for imperceptible fundamental particles and the like, and the scientific image omitting terms for artifacts, social objects, and the like), they, in fact, do not employ all possible categorial terms. An account can only offer a complete description in terms of that framework in the sense of covering all the things in those categories. The scientific and manifest images presuppose different sortal frameworks and hence they cannot be deemed to be complete in any way that renders those rivals (Thomasson $2007,148)$. Consequently, acceptance of the scientific image does not require rejection of the ontology of the manifest one. Therefore, even if each categorial framework purports to be complete in some sense (i.e. offering a complete account of things of those sorts), they still do not purport to be complete in some absolute and 'external' sense.

Of course, conditions of application and/or coapplication for some terms may be built upon others [as, e.g., the conditions for application and coapplication of nation terms may be built upon those for person-terms, landmass terms, etc.; (Thomasson 2009, 451)], making some more basic than others. In this respect, since the manifest image and scientific image employ different characteristic sortal terms, they are each concerned with different categories of entities, and hence with different most fundamental ones. So, even if each categorial framework purports to offer its own account of what the fundamental category of the world is in some sense, they still do not purport to offer its own account of what the fundamental category is in some external and absolute sense.

In sum, the supposed rivalry between scientific and manifest image accounts of what there is can only arise based on the assumption that each image purports to offer (at least in principle) a true and complete account of what there is (Sellars 1963, 20). But, properly understood, neither of the two images (with its own characteristic sortal terms) can really purport to offer a complete account of what there is. Therefore, there is no obvious sense in which either the scientific image or the manifest image may legitimately purport to be complete in a way that would rule out the other. In the same way, each image purports to offer (at least in principle) a true account of what the fundamental category of the world is. However, each 
image (with its own characteristic sortal terms) can purport to offer a true account of what the fundamental category of the world is in some sense. But, properly understood, neither of the two images (with their own characteristic sortal terms) can really purport to offer a true account of what the fundamental category of the world is in some absolute and 'external' sense.

At this point, one option can be to explore the possibility of meshing the common sense framework with the physics one by constructing some metaphysical relations; another, as we shall see, is to radically remove the necessity for positing certain such relations cleaving them entirely apart, as Thomasson does. According to the first way, the two frameworks are kept in touch with each other. Trying to find a common fundamental category utilized in both scientific and common sense descriptions, Cumpa seems to move exactly in that direction. First, Cumpa dismisses the possibility that, among others, the categories of substance or set are able to achieve this goal. Likewise, Thomasson rejects the possibility to appeal to a common notion of, for instance, 'physical object' or 'occupant of a spatio-temporal region,' insofar the former finds no place within physics itself, and the latter is hardly common in everyday descriptions. Nevertheless, unlike Thomasson who maintains that the conceptual frameworks and ontologies of common sense and physical science are so different that it is hard to find a common conceptual or categorial ground, Cumpa attempts to advance a positive account. Indeed, he argues for the category of 'facts' as able to build such a bridge between the two images (at least according to this first interpretation of his argument). Cumpa's issue then is to establish whether such a relationship effectively holds while neither reducing the common sense framework to the scientific one, nor considering the general metaphysical characterization of such relationships in terms of 'grounding. ${ }^{9}$ To some extent, he takes this relation seriously, metaphysically speaking, without the kind of

9 Say: $a$ is said to be grounded in $b$ in the sense that $a$ holds in virtue of $b$ (without being the case that only $b$ exists). Thus, for example, the 'fact' of there being a table in front of me (or Eddington) is grounded in facts about the relevant aggregate of quantum particles in the sense that the former fact holds in virtue of the latter [see (North 2013, 26)]. 
dependence that 'in virtue of' signifies and he indicates, in at least a preliminary way, how an appropriate metaphysics might be constructed on this basis. Now, explanatory relations, such as the one he outlines, offer a broader framework than, say, causal accounts, whilst not trivializing the relationships as deductive accounts do [see (Thomasson 2007)].

Anyway, endorsing this solution one could face with some problems. As we have seen, claims involving 'facts' (as well as 'physical objects,' 'things,' etc.) are truth-evaluable just if the speaker uses it sortally. And 'facts,' like 'things' or 'objects,' (although it seems to be used non-sortally) is used as a sortal just if it is associated with application and identity conditions outlining what it would take for there to be a fact in a given situation, and under what conditions we would have the same fact again. Clearly, each framework could replace 'facts' with one sortal from its own framework, but then neither is purporting to offer a complete account of 'facts,' but just of 'facts' of that sort. Sortal uses of 'facts' will not help bolster claims to absolute fundamentality either, since, if 'facts' is being used as a sortal (even if it is understood as the fundamental category in that framework) it does not rule out the possibility there being different fundamental categories in other frameworks (for other sortal uses of 'facts'). And besides, if each uses 'facts' in this covering sense that presupposes a different range of sortals, then their resulting accounts of what the most fundamental category is cannot even be true rivals. ${ }^{10}$

In spite of this supposed incommensurability between the two images, Cumpa seems to offer a picture able to retain the category of 'facts' as fundamental and, at the same time, shared by both the realist and the physicalist languages. The dilemma is effectively resolved insofar 'facts' is understood as a compound category which has the highest category of both languages as constituents. In this way, the manifest and the scientific images turn out to be not two different frameworks, but two branches of a broader one which has the category of 'facts' as the most fundamental

10 It must be noticed that arguments put forward in this Section are also available for any other metaphysical category (e.g. events, processes or states of affairs) insofar as the cross-sectional feature required by the fundamentality mentioned in relation to 'facts' are not met by other metaphysical categories either. 
one. That could be a manner of conceiving what he calls 'language of metaphysics.' In this light, Cumpa's proposal could be taken as a viable option and a plausible answer to the original question: "What are the fundamental inhabitants of the world?" Moreover, this approach would also undermine the kind of reductive analysis that physics appears to push us toward. Nevertheless, in order to demonstrate the non-incommensurability of the two frameworks at hand, surely further work needs to be addressed. Complicated issues arise about whether this metaphysical maneuver is really available, but we do not need to address them here, for even if such a move is possible, it will help revive neither a rivalry nor compatibility between them, strictly speaking. ${ }^{11}$

\section{The external reading}

As we have seen, the sortalist position gives us reason to doubt that each of the two images could legitimately purport to provide an account of what the fundamental category absolutely is. Since each image (with its own characteristic sortal terms) purports to offer its own account of what the most fundamental category is in some sense, we cannot legitimately say they provide rival accounts of what the fundamental category is. Nevertheless, there is at least another possible interpretation of Cumpa's project. Employing Carnap's terminology, I will call it 'external reading.' Indeed, one might try to present the conflict in terms of some neutral sense of 'facts,' external to any framework that establishes the rules of use for such a term. But 'facts,' in that sense, would not then be a sortal term and could

11 A related worry is that, even if a category that covers all possible (first-order) categorial concepts is possible, set-theoretic-style paradoxes, such as a Russell-style paradox, quickly arise. We can postulate a category that covers all possible (firstorder) categorial concepts ('organism,' 'artifact,' etc.) and all of their compliants, but then there are possible (second-order) categorial concepts which are not covered (e.g. first-order category), so there is a sense in which we have not covered absolutely universally. So that it seems there is no category of which one could rightly claim to be absolutely universal. But more than that, it seems that we can "form no definite conception of the totality of all objects which could be spoken of" (Dummett 1973/1981, 566-67, 582-83). 
not be used to establish reference. That is, if 'facts,' in its neutral use, is not a sortal term, then, on the sortalist view, it cannot enable us to establish reference to something, about which science and common sense may then agree or disagree. Consequently, we cannot legitimately say that 'facts' is the fundamental category of the world, where 'facts' is being used neutrally. For if 'facts' is not being used as a sortal term, it does not come associated with application conditions needed to establish if it is properly applied and the identity criteria (coapplication conditions) needed for counting. Thence, we have serious reason to doubt that such alleged neutral uses of 'facts' could be used to answer the question about what the fundamental category of the world is. The question "is 'facts' the fundamental category of the world?", understood externally (external to any framework), turns out to be an ill-formed, unanswerable question. Likewise, claiming that "facts' is the fundamental category," so understood, will also result meaningless and devoid of any cognitive content. In sum, if 'facts' is really used neutrally in attempts to state these debates, then that should raise our suspicions that the claims involved are incomplete and not truth-evaluable. In the same way, that should raise our suspicions that the corresponding metaphysical questions are ill-formed and unanswerable, and that apparently competing answers to them do not really conflict with each other.

Nevertheless, even though they so understood result to be cognitively meaningless and fail at bipolarity (they have no true values), they may still have a different sort of 'meaning:' a normative one. Indeed, the statement "the fundamental category is that of 'facts," in its external use, may express the commitment to adopt a framework in which 'facts' occurs as the fundamental categorial term (in that particular framework). ${ }^{12}$ And, perhaps, such a framework could be identified with what Cumpa calls 'the metaphysical language.' Anyway, this external use says nothing about that framework itself, what actually it is, how it is constituted and whether it is a possible language at all. Moreover, if the 'metaphysical language' is taken to be different from both the realistic and the scientific language, it will be deprived of any relationship with them, and to a certain extent, it will be

12 For an expressivist account of ontological claims and questions, taken externally, see (Kraut 2016). 
incommensurable with both of them. Thus, 'facts,' understood as the fundamental category of the metaphysical language, will certainly not play that role also in the other languages at stake. However, if Cumpa has in mind some kind of relationship (even some kind of metaphysical relationship) between the alleged metaphysical language and the two other mentioned, I think he should make it explicit, specifying or at least clarifying the supposed contact point.

Furthermore, if this is effectively the most reliable interpretation of Cumpa's proposal, appealing to epistemic virtues (as Cumpa suggests when he argues for the greatest explanatory power of 'facts') does not seem to be a possible strategy to be followed. According to the present view, no framework can be deemed more correct or valid than any other. Or better, since speaking of correctness (or validity) here does not apply at all, then it is applied in the same way. Likewise, among the frameworks, there is none that is uniquely best (viz. the 'correct' one). But this formulation certainly does not suggest that the frameworks are all equally good: definitely, a framework might be better than another according to some goals. The linguistic rules we adopt need not be arbitrary, given our purposes, since some rules may serve those purposes better than others. Some languages may be better than others for various purposes and there may be practical issues, or reasons, involved in determining which language is better for that given purpose (or set of purposes). Hence, it follows that virtues for opting for one language over another cannot be epistemic but at most practical in character.

It is also important to notice that, insofar as such practical virtues (or non-epistemic values) act like norms or standards of evaluations, these comparative judgements, of which frameworks are better than which, turn out to be normative. Or in other words, even when based in part on non-normative descriptions, they can only be made from those norms. Therefore, such judgements of betterness must be understood as involving a hidden relativity to a norm; in particular, some practical value or virtue. In this sense, it may be quite reasonable to engage in debates about the merits of these various proposals, practical proposals about which set of concepts (or revisions of our current concepts) would best serve some particular set of purposes, though it would be misguided to think of these as substantive debates about how the world is actually made up. 
This reading is very close to how Carnap suggests we should understand external ontological questions in general: as practical questions about the advisability of adopting certain linguistic forms. Although, according to Carnap, external questions have no cognitive content at all, they are still significant questions. Indeed, they are not meant to be questions about what there is in the world, but rather questions about what we should do: questions about which framework we ought to use according to some practical goals. Correspondingly, ontological claims, taken externally, are to be conceived as implicitly answering practical questions about whether or not to accept the related linguistic framework as a whole. And those, of course, are quite different from the (internal) cases in which "we have to make the choice whether or not to accept and use the forms of expression in the framework in question" (Carnap 1950, 207). Therefore, the relevant distinction turns out to be the one between the theoretical issues about what true statements (including existence claims) may be made using a given linguistic framework and the purely practical issues of which linguistic frameworks to choose and adopt. And the choice of a language is nothing but a purely practical choice about what tool to use, rather than as a theoretical decision that is either correct or incorrect: "it does not need any theoretical justification because it does not imply any assertion of reality" (Carnap 1950, 214). In short, if we take external categorial questions literally (as attempted theoretical or factual questions), they are ill-formed pseudo-question. The best we can do is then to consider them as implicitly asking questions about whether or not to accept and use a given categorial framework (with its own categorial structure and fundamental categories).

But, Cumpa does make no reference at all to the practical purposes for which such a metaphysical language should be adopted. Might these be, perhaps, the practical advantages of coping with today's increasingly pressing demand to incorporate scientific expressions with those already in use in ordinary language? Anyway, if that is precisely how Cumpa intends the role of the claim that "facts' is the fundamental category of the world" and the function of 'metaphysical language' in general, then, I guess, he should at least mention them, as long as it is possible. In that direction, in order to reveal what they actually might be, further investigations are certainly still needed. 


\section{Conclusion}

The distinction between structure and content is one that has arisen repeatedly in discussions over the relationship between the scientific and the everyday ontology, but it evaporates as far as Eliminativism is concerned, since all relevant content is taken to be cashed out in structural terms. However, according to Thomasson, Eddington's standpoint is undermined because, she claims, there is a "lack of conflict between the merely structural properties physics imputes to the world and the qualitative content involved in ordinary world descriptions" (Thomasson 2007, 139). Insofar as the two manifest and the scientific images involve different linguistic/categorial frameworks, we are not in a position to compare them and then it would be a mistake both to maintain that there is and that there is not a conflict between them. ${ }^{13}$

Cumpa (2014) adopts a different strategy. He argues neither for the incommensurability of the two languages nor for the reducibility of the ordinary level to the scientific level of thinghood. Instead, he attempts to find a category able to reconcile the two images. He identifies the category of 'facts' as the only one which meets this requirement: the best category to account for the relation between the ordinary world and the physical universe. As he defines it: "The fundamental category of the world." Nevertheless, it turns out to be not clear at all how he suggests the relationship between the alleged category of 'facts' and the two descriptions of the world ought to be understood.

The aim of this paper has been to outline two possible ways in which Cumpa's factualist approach could be conceived. Both, however, present some difficulties, or at least they need further investigations. According to

13 In the same spirit, the general view I have been elaborating and defending in this paper is that many manifest-image descriptive expressions which scientific naturalists have relegated to second-class citizenship in discourse are not inferior, just different. It just is not the case that everything we talk about in the manifest image that exists at all is something specifiable in the language of an eventual natural science and that "in the dimension of describing and explaining the world, science is the measure of all things, of what is that it is, and of what is not that it is not" (Sellars 1956, §41). 
the first one, common sense image and scientific image are taken to be two branches of a single broader linguistic framework, which he calls 'metaphysical language.' Along these lines, 'facts' turns out to be the fundamental category in that language and, as such, a category shared by both images. Nevertheless, rather than a category common to the realist language and the scientific language, 'facts' is considered to be a compound category, which has the highest category of both ('arrangement of particles' and 'perceptual properties') as constituents. In other words, 'facts' should be understood as the fundamental category of a broader framework (the metaphysical language), but at the same time as constituted by the highest categories of both those narrower frameworks (the realist language and the scientific language). Appealing to a sortalist standpoint, in Section 3, I have tried to reveal the limits of this way of conceiving Cumpa's proposal.

Alternatively, in Section 4, I have introduced what I called an 'external' reading. Here, evoking Carnap's well known distinction between 'internal' and 'external' ontological questions, I have presented Cumpa's claim that "facts' is the fundamental category of the world" as external to any linguistic/categorial framework and the term 'facts' as used in some neutral sense (as a non-sortal term). I have argued that such an external categorial statement is meaningless as devoid of any cognitive content. Following Carnap, I have suggested that at best it might be understood as a normative claim. That is, not as a descriptive claim, but rather as a claim about what we should do. In particular, a statement about what categorial framework we ought to adopt. In this respect, it will express commitments to the adoption of a categorial framework in which the fundamental category is that of 'facts.' Then, I have tried to show how such a reading clashes in principle with Cumpa's conception of a 'metaphysical language.'

In conclusion, whichever of the two interpretations is closer to Cumpa's original purpose, further explanations and clarifications, I think, are needed. I hope Cumpa is willing to take up my suggestions and to address these issues developing his account in one direction or another.

\section{Acknowledgements}

I would like to thank Javier Cumpa for his helpful comments on this paper.

Organon F 26 (2) 2019: 186-206 


\section{References}

Carnap, Rudolf. 1950. "Empiricism, Semantics, and Ontology." Revue Internationale de Philosophie 4: 20-40. Reprinted as a supplement to: Carnap, Rudolf. 1956. Meaning and Necessity: A Study in Semantics and Modal Logic, enlarged edition. Chicago: Chicago University Press.

Cumpa, Javier. 2014. "A Materialist Criterion of Fundamentality." American Philosophical Quarterly 51 (4): 319-24.

Dennett, Daniel C. 1991. "Real Patterns." Journal of Philosophy 88 (1): 27-51. https://doi.org/10.2307/2027085

Dummett, Michael. 1973/1981. Frege: Philosophy of Language, $2^{\text {nd }}$ edition. Cambridge, MA: Harvard University Press.

Eddington, Arthur S. 1928. The Nature of the Physical World. Cambridge: Cambridge University Press.

Fodor, Jerry. 1974. "Special Sciences: The Disunity of Science as a Working Hypothesis." Synthese 28 (2): 97-115. https://doi.org/10.1007/BF00485230

French, Steven. 2014. The Structure of the World: Metaphysics and Representation. Oxford: Clarendon Press. https://doi.org/10.1093/acprof:oso/9780199684847.001.0001

Geach, Peter. 1962/1980. Reference and Generality, $3^{\text {rd }}$ edition. Ithaca, NY: Cornell University Press.

Kim, Jaegwon. 1992. "Multiple Realizability and the Metaphysics of Reduction." Philosophy and Phenomenological Research 52 (1): 1-26. https://doi.org/10.2307/2107741. Reprinted in: Kim, Jaegwon. 1993. Supervenience and Mind. Cambridge: Cambridge University Press.

https://doi.org/10.1017/CBO9780511625220.017

Kraut, Robert. 2016. "Three Carnaps on Ontology." In Ontology after Carnap, edited by Stephan Blatti and Sanda Lapointe, 31-58. Oxford: Oxford University Press. https://doi.org/10.1093/acprof:oso/9780199661985.003.0003

Lowe, E. Jonathan. 1989. Kinds of Being: A Study of Individuation, Identity and the Logic of Sortal Terms. Oxford: Blackwell.

McKenzie, Kerry. 2011. "Arguing Against Fundamentality." Studies in History and Philosophy of Science, Part B 42 (4): 244-55.

https://doi.org/10.1016/j.shpsb.2011.09.002

McKenzie, Kerry. 2014. "Priority and Particle Physics: Ontic Structural Realism as a Fundamentality Thesis." British Journal for the Philosophy of Science 65 (2): 353-80. https://doi.org/10.1093/bjps/axt017

North, Jill. 2013. "The Structure of a Quantum World." In The Wave Function, edited by David Z. Albert and Alyssa Ney, 184-202. Oxford: Oxford University Press. https://doi.org/10.1093/acprof:oso/9780199790807.003.0009 
Putnam, Hilary. 1975. "Philosophy and Our Mental Life." In Mind, Language and Reality: Philosophical Papers, vol. II, edited by Hilary Putnam, 291-303. Cambridge: Cambridge University Press.

https://doi.org/10.1017/CBO9780511625251.016

Sellars, Wilfrid S. 1956. "Empiricism and the Philosophy of Mind." In Minnesota Studies in the Philosophy of Science, vol. I, edited by Herbert Feigl and Michael Scriven, 253-329. Minneapolis, MN: University of Minnesota Press.

Sellars, Wilfrid S. 1963. "Philosophy and the Scientific Image of Man." In Science, Perception, and Reality, edited by Robert Colodny, 35-78. London: Routledge \& Kegan Paul.

Stebbing, Susan. 1937. Philosophy and the Physicists. London: Methuen and Co.

Thomasson, Amie. 2007. Ordinary Objects. New York: Oxford University Press. https://doi.org/10.1093/acprof:oso/9780195319910.001.0001

Thomasson, Amie. 2009. "Answerable and Unanswerable Questions." In MetaMetaphysics, edited by David Chalmers, Ryan Wasserman, and David Manley, 444-71. Oxford: Oxford University Press.

Wilson, Mark. 2008. Wandering Significance. Oxford: Oxford University Press. https://doi.org/10.1093/acprof:oso/9780199269259.001.0001 